\title{
Evaluating the effect of organization culture on the successful execution of strategies: Case study of Payam-e-Noor university
}

\author{
Babak Monzavi $^{\mathbf{a}^{*}}$, Vahidreza Mirabi ${ }^{\mathrm{b}}$ and Ali Jamshidi ${ }^{\mathrm{c}}$
}

\author{
${ }^{a}$ M.A. of Executive Management, Department of Executive Management, Electeronic Branch, Islamic Azad University, Tehran, Iran \\ ${ }^{b}$ Faculty member, Central Branch, Islamic Azad University, Tehran, Iran \\ ${ }^{c}$ Faculty member, Lavasanat Branch, Payam-e-noor University, Tehran, Iran \\ C H R O N I C L E \\ A B S T R A C T
}

Article history:

Received January 14, 2013

Received in revised format

30 May 2013

Accepted 6 June 2013

Available online

June 92013

Keywords:

Power Distance

Uncertainty Avoidance

Individualism

Masculinity

Strategy Effectiveness

\begin{abstract}
In this research, we use Hofstede method and Noble's framework in strategy execution to evaluate the effect of organization culture on the successful implementation of strategies in a case study of Payam-e-Noor University of Iran. Data Collection is performed with the standard Hofstede survey, an evaluation tool for organization culture, and researchers' survey tool to evaluate the effective implementation of strategies. The reliability coefficient was calculated as 0.846 using the Cronbach alpha. The target population includes 600 senior managers of Payame-Noor university of Iran at the time of data collection Cochran formula was used to calculate the required sample number of 120 individuals. The results show that according to the Hofstede dimensions, the dominant cultural aspects of high power distance, uncertainty avoidance, collectivism, and femininity were identified. The first two have a direct influence on effectiveness of strategies. While individualism is known to have an invert effect on effectiveness of strategies, no connection was identified between masculinity and effectiveness of strategies, and thus, this theory was not confirmed in this research.
\end{abstract}

\section{Introduction}

During the past few years, there has been growing interest on strategic view and it plays important role for management. Among environmental elements, culture has also been considered as an approach in the strategic management process. Many people believe that the capabilities of a society to apply a strategy depends on the software and hardware foundations of that society, as culture and cultural norms are software foundations of any society (Tampson, 2003:418). This describes how societies and organizations, even with weak planning and strategy, are able to succeed in the implementation of strategies. Successful strategy implementation needs the support of the dominant culture of the society or firm. This is why in almost every pattern of strategy; culture is considered as one of the important elements (A'arabi \& Hedayati, 2010).

*Corresponding author. Tel: +98 9362652383

E-mail addresses: monzavibabak@yahoo.co.uk (B. Monzavi) 
If strategy is what a particular firm is aiming to apply and organization is considered as a tool, which shows how to apply a strategy, guiding believes demonstrates why a firm aims to implement a strategy. Success or failure of the strategy depends on its consistency with the everyday beliefs of the staff, structure, and existing systems within an established organization (Davis, 1984). Attention to organizational culture plays important role in clarification and execution of organizational strategies and senior managers need to have a particular emphasis on it, otherwise they will be in touble in implementing the strategy. On the other hand, human resource managers should attempt to create the necessary alignment between senior management and culture of the staff. This is considered the most complex and difficult task in the field of human resource management (Mirsepasi, 2004).

The growing environmental vagueness needs the governmental and non-governmental as well as societies to think and act, strategically. For implementing the strategic thinking, it is essential to verify the role of organizational culture as one of the key factors of success. When strategies change, culture reinforces the commitment and increases the efficiency in an organization. According to Peters and Waterman (2004), one of the most well-known theorists of organizational strategy is to create an evolution in the competitive world with his sentence and there are always four barriers as follows,
1. The Vision Barrier,
2. The People Barrier,
3. The Resource Barrier,
4. The Management Barrier.

While senior managers are responsible for setting the strategies, implementation of them needs the cooperation of everyone, from middle managers to staff in various departments (Kaplan \& Norton, 2001). Strategies are implemented within an organization, therefore, it is expected to verify a deep relationship between organizational culture and strategy. Strategists need to attempt to create and protect various aspects of the existing culture, which support the new strategic recommendations. The aspects of the existing culture opposing the suggested strategy should be detected (David, 2010). This concept has obtained the necessary attention of academics and executive managers, to concentrate more on integrating the management processes based on strategic planning. The following challenges forces the state universities to use strategic planning:

1. Ability to survive in the 21 Century and beyond,

2. Coping with new models in the provision of higher education,

3. Addressing the competitive issues spawned by the rise of private universities,

4. Growing imperative to provide quality human Resources to meet national developmental needs.

These challenges are becoming increasingly daunting and the antidote seems to lie in the implementation of strategic planning (Ofori \& Atiogbe, 2012). Considering the outcomes of Payame-Noor University, as one of the state universities in Iran, in recent years, with more than a million students in 2011, covering around 30\% of total nationwide students, 500 academic centers around the nation, and achieving the second place in Asia and 6th place worldwide among open and distance education institutions, it is necessary to study this university.

Many people believe strategic management as synonymous to strategic planning. Strategic management is the art and science of compilation, execution, and evaluation of cross-functional functional decisions, which make an organization capable of reaching its objectives (Pearce \& Robinson, 1991). Strategic management is the description of a set of decision and actions leading to the compilation and execution of plans designed to reach an organization's objectives (Hoskisson et al., 2008). The strategic planning process is an objective and systematic method for important 
decision makings within organizations. In strategic management, information is organized in a way to permit effective decision making under uncertainty. Strategic planning leads to increased flexibility, agility, and capacity to adapt to changes. Most of the difficulties of strategic management occure during the execution. To solve them, various combinations of skills and capabilities exist. Theorists of organization study the impact of organizational culture on various aspects of organization, considering various elements, features, and variables of organizational culture. Robbins (2005) showed the individual creativity, risk toleration, directing, integrity, management relations, control, identity, incentive system, conflict toleration, and communication patterns that distinguishes the cultures from one another. However, Hofstede has studied the national and organizational culture from a completely various perspective where organizations are symbols of bigger cultural systems and four dimensions of national culture, including power distance, uncertainty avoidance, individualism, and masculinity, impact the organizational culture (Robbins, 2005). In this work, our goal is to study these dimensions of organizational culture on the successful execution of strategies.

\section{Literature review}

\subsection{Organizational culture}

1980s marked a new emerge for investigation on organizational culture and it began on the subject of corporate culture. Peters and Waterman (2004) emphasized that organizational culture is set of values followed by all the staff, and general rules, which convince every one of them. Culture has also been recognized as a set of believes, thoughts, customs, manners and dominant values of a society. In other words, culture is described in society, group, and within their interactions, and expresses the way people of the group and society communicate and interact (Joseph \& Igor, 1999).

\section{Hofstede's View of Organizational Culture}

One of the agreed upon takes on the subject of organizational culture is extracted from the idea that organizations can be considered as symbols of greater cultural systems. Hofstede used this idea to investigate IBM Corporation, as one of the biggest firms in the world, which was active in more than 40 countries at the time of the study. He examined the work values survey data, compared the data among IBM's subsidiaries, and surveyed the differences of national cultures within IBM organizational culture. He categorized the differences in the data collected from various IBM international subsidiaries based on four dimensions of power distance, uncertainty avoidance, individualism, and masculinity (Hatch, 2006).

\section{Power Orientation or Power Distance}

Power orientation or power distances are the extent in which members of a society accept the inequality in power distribution. In societies in which there is a wide power gap, powerful individuals are respected and all employees believe that those on top of the hierarchy are right and they have the right to decide. France, Spain, Mexico, Iran, Japan, Brazil, Indonesia, and Singapore are among the countries where powerful individual are relatively respected. However, where power gap becomes narrower, organizational position in the organizational hierarchy becomes less important and staff may question the mandates of superiors and may even refuse to follow them. In these countries, employees follow a leader not because he has the right to order, but because they think what he says is right and in line with their benefits. Hofstede studies demonstrated a narrow power gap in the United States, Austria, Denmark, Ireland, Norway, Germany, New Zealand, United Kingdom, and Canada (Esmailpour, 2011).

Uncertainty Avoidance refers to the ways societies have learned to deal with uncertainty. For instance, technology is implemented to defend against environmental uncertainties (like earthquake resistant 
structures in earthquake prone regions). Laws also help us defend ourselves against the uncertainties in attitudes of other members of the society. Religion is another tool to help us adopt the uncertainties against which we are defenseless. Hofstede claimed various societies have various tolerance levels for uncertainty, ambiguity and risks. This difference can be translated to the difference in the way the members of these societies feel threatened by uncertainty, ambiguity and risk. In societies with less uncertainty avoidance, individuals admit creative ideas and abnormal behaviors. However, in societies with higher uncertainty avoidance, people resist them. Hofstede findings demonstrated that uncertainty avoidance was higher in Greece, Portugal, and Japan and lower in Singapore, Hong Kong, and Sweden (Hatch, 2006).

Individualism (Masculinity \& Femininity): This item is associated with how much a person is expected to function independent from other members of a society. Hofstedee implemented some evidences of individualism against collectivism, where people lived together (Hatch, 2006). Esmailpour calls this social orientation and defines it as the individual's belief in the relative importance of himself as an individual and the groups he belongs. Two extreme ends of social orientation are individualism and collectivism. Individualism puts the individual in the first place. Individualists assume a high level of respect for themselves and their independence. These people usually prioritize their professional objectives based on organizational goals, and evaluate the decision based on how they influence themselves. According to Hofstede studies, people in the United States, United Kingdom, Australia, New Zealand, Canada, and Netherlands are relatively individualists. Collectivism is the opposite of individualism and put the group in the first place. Societies that believe in collectivism are shaped based on social networks and include extended families, tribal life, and similar. People are expected to rank the collective benefit of the group to their personal objectives, interests, and success. When group faces a failure in these societies, members of the group take it personal. In addition, group members adopt themselves to the group with least possible tension and conflict. Hofstede work demonstrated that people of Mexico, Greece, Hong Kong, Taiwan, Peru, Singapore, Colombia and Pakistan are relatively collectivist (Esmailpour, 2011).

Goal-orientation This orientation is associated with the way individuals are inspired to work toward various goals. On one side, goal orientation is the goal-oriented aggressive behavior, shown by individuals for whom material possession, money, and self-expression plays essential. On the other side, it is the goal-oriented passive behavior, which assumes high social value for social relations, quality of life, and attention to other members of the society. According to Hofstede's viewpoint, in cultures with goal-oriented aggressive behavior, the social role of men and women are separated, completely. In these societies men are expected to work in the traditional masculine jobs, while women are expected not to work out of the house and to focus on family. If women need to work outside, it should be in the traditionally feminine jobs. Based on Hofstede's results, people of Japan have demonstrated a goal-oriented aggressive behavior. This behavior has a reasonable level in Germany, Mexico, Italy and the United States. In countries with goal-oriented passive behavior (female-centric societies), both men and women take variety of jobs, regardless of their sex. Finland, Norway, Sweden, Denmark and Netherlands are among these societies (Esmailpour, 2011).

Time-orientation This kind of orientation is associated with members of a culture who pursue longterm or short-term perspectives in their work, life and other social aspects. Long-term view assumes a higher value for commitment, hard work, providence, and assiduity, and it can be seen in Japan, Hong Kong, Taiwan, and South Korea. Countries like Pakistan and South Africa are more focused on past and present, respect the customs and their social commitments. According to Hofstede, the United States and Germany have a middle-term time orientation (Esmailpour, 2011). According to Hofstede's study, it can be said that people of Iran have the following cultural features:

- High power distance, which means hierarchies are easily accepted,

- Relatively high uncertainty avoidance, but lower than the power distance, 
- Masculinity, if defined as violent social relations, is not strong. In other words, the society is relatively emotional and sensational,

- Strong individualism, which means people prioritize their goals to the goals of the society.

It seems that the results of Hofstede's study are very credible but note that these features change in different regions of Iran because of the differences in ethnic cultures (Mirsepasi, 2010). The importance of Hofstede's study is not only the fact that he identified the cultural differences among countries, but also he showed that organizational culture is an entrance for the social-national dominance over organizations. Cultural-national features can be considered as part of the conceptual texture shaping the organizational culture. The dimensions of cultural differences introduced by Hofstede give us some information about the presumptions and believes influencing organizational cultures (Hatch, 2006).

\subsection{Strategy Execution}

Sashital and Wilemon (1996) have pointed out that some terms synonymous with "implementation", such as "execution", and "actualization of goals" are used in the management literature, but are not frequently applied by managers themselves. Thompson and Strickland (1998) have stressed that strategy-implementation/strategy-execution task is the most complicated and time-consuming part of strategy management. Thus, it can be considered that strategy-implementation would not different from strategy-execution. Yang et al. (2009) explained that there was no agreed upon definition for strategy execution. However, they still identify three distinguishable concepts for strategy execution: the first perspective focuses on the procedural viewpoint and uses strategy execution as a series of accurately planned consecutive steps. The second perspective defines strategy execution as an almost coordinated operations (but often parallel) and behavioral analysis of these operations. Some authors combine the procedural and behavioral with the operational perspective, to create what is called the hybrid point of view.

In some of the research works, the importance of personal factors on strategy execution is emphasized; while in others emphasize is on all the relevant environmental factors. Yang et al. (2009) identified 9 personal factors influencing strategy execution, including: the strategy formulation process, the strategy executors (managers, employees), the organizational structure, the communication activities, the level of commitment for the strategy, the consensus regarding the strategy, the relationships among different units/departments and different strategy levels, the employed implementation tactics, and the administrative system in place. The second stream of research analyzed multiple factors together within a single framework or a model. Both Skivington and Daft (1991) and Noble (1999b) categorized the execution factors in two dimensions including framework and process, but with different content in each category. Skivington and Daft (1991) specified two generic kinds of strategic decisions, distinction and lower costs, to be executed using two organizational methods of framework and process. Rules and resources, and an organizational process with interactions, concepts and formalities specify an organizational framework. The results showed that execution of these two strategies employs several variables, and that there can be a particular pattern of variables for each strategy.

Studies of Skivington and Daft (1991) and Noble (1999b) are based on strategy execution from the structural view emphasizing organizational structure and control methods and an interpersonal process view emphasizing on strategic consensus, independent strategic behaviors, diffusion perspective, execution and leadership style, communication and interaction processes. Noble and Mokwa (1999) added a third view, the individual-Level Processes View, emphasizing on cognition, organizational roles and commitment besides the structural and interpersonal process view. Pettigrew's studies categorized the execution factors in more groups, including strategic content, context (organizational context: organizational structure, organizational culture, and environmental 
context: general uncertainty and uncertainty in the task environment), process (operational planning, resources, people, communications, control and feedback) and strategic outcome (Okumus, 2001).

Okumus (2001) also expanded the above framework and added three new variables to it. The summarized implementation framework has four sections: content (strategic decision making, executing different projects), context (internal context: organizational structure, organizational culture, organizational learning; external content: environmental uncertainty in the general and task environment), process (operational planning, resources allocation, people, communications, monitoring and feedback, external partners) and outcome (tangible and intangible outcomes of the project).

Yang et al. (2009) stated that the strategic projects under study were executed without a proper conformity between strategy and execution variables. It appears that any problem or incoherence in one variable influences other variables and consequently impacts the success of execution process. This creates an unsolvable challenge for reaching the coherence among all execution variables in complex and dynamic contexts. Execution variables are a combination of all working variables, which make the successful execution process of strategy possible. Yang et al. (2009) emphasized that studies in the second group gathered various factors in one framework or model. Therefore, not only do they discuss categorizing the execution variables, but also they organize them in terms of temporal relationships. Noble's strategy implementation framework is organized around four major stages of the implementation effort-pre-implementation, organizing the implementation effort, managing the implementation process, and maximizing cross-functional performance. There are five managerial levers to apply these stages: goals, organizational structure, leadership, communications and incentives. Based on Noble's theory, management changes these factors during the execution stages.

Noble's Model

Pre-implementation stage

1. Goals: Make sure all the mangers are aware of the organization's strategic goals

2. Organizational Structure: Operational sections have resources to be capable of cooperating in strategy execution.

3. Leadership: Expand the employees' knowledge and acknowledge operational sections.

4. Communications: Keep the cross-functional functional communication to promote understanding and acknowledging

5. Incentives: Reward for developing cross-functional functional skills

Organizing the execution effort

1. Goals: introducing the objective of the strategies based on strategic vision,

2. Organizational structure: Establish a formal execution unit, and make sure of its visibility to all the organization,

3. Leadership: Establish a hero, someone who has a cross-functional functional power, and general respect of the organization members,

4. Communications: Discuss and establish the details of early implementation in this process,

5. Incentives: Develop the incentives based on performance and time for the implementation team, while reducing the traditional functional incentives,

Managing the implementation process

1. Goals: Maintain the flexibility to adapt to the goals based on the environmental changes,

2. Organizational structure: Make sure each level of structure affected by the implementation has equal attention, 
3. Leadership: Make sure the leaders show equal concern for each operational level,

4. Communications: Update the implementation team frequently with the progress and changes in the Objectives,

5. Incentives: Set the incentives based on the strategy and environmental conditions changes during the implementation.

Maximizing the performance of cross-functional

1. Goals: Development and emphasize on mutual objectives to encourage cross-functional functional coherence,

2. Organizational structure: Temporarily suspend regular tasks of the implementation key team members to let them focus on implementation effort,

3. Leadership: Balance visible and charismatic leadership, while preserving the independence of implementation efforts in functional level,

4. Communications: Communicate implementation progress across the entire organization to foster buy-in,

5. Incentives: Establish visible and consistent cross-functional functional rewards for successful execution efforts.

In this work, the model of Noble is applied to evaluate the successful strategies of Payam-e-Noor University.

\section{Conceptual model}

As stated in the abstract/introduction the subject of this research is to use the Hofstede view, which includes power distance, uncertainty avoidance, individualism, and masculinity, to evaluate the effect of organizational culture on successful execution of Payam-e-Noor University strategies. Therefore, independent variables include "Power Distance”, "Uncertainty Avoidance”, "Individualism” and "Masculinity" and "effectiveness of strategies" is the dependent variable. In the strategy section, the framework used is based on the model of Noble. Model of Noble is also used to design the survey.

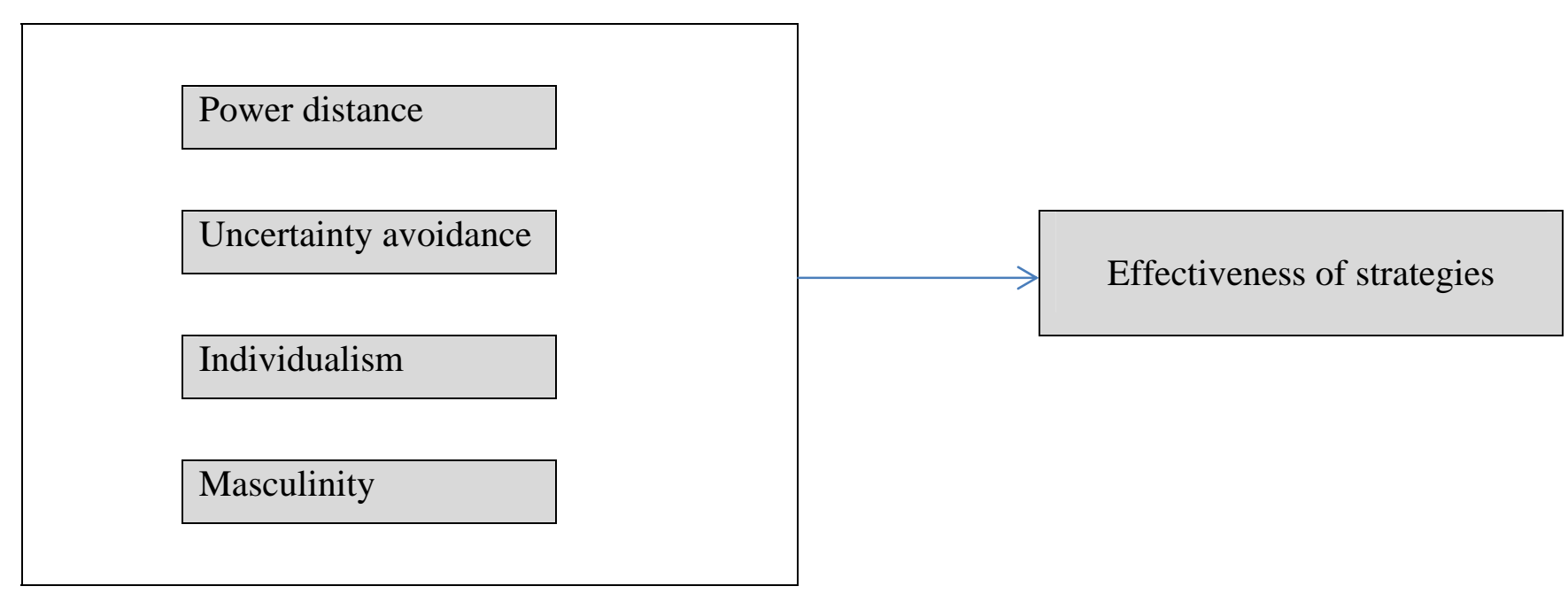

Fig. 1. Conceptual Model of the Research (Robbins, 1990) 


\section{The proposed hypotheses}

Primary thesis: organizational culture influences the effectiveness execution of Payam-e-Noor university strategies.

Secondary thesis:

1. Power distance influences the effectiveness execution of Payam-e-Noor university strategies.

2. Uncertainty Avoidance influences the effectiveness execution of Payam-e-Noor university strategies.

3. Individualism influences the effectiveness execution of Payam-e-Noor university strategies.

4. Masculinity influences the effectiveness execution of Payam-e-Noor university strategies.

\section{Research method}

This is a descriptive research of two variable correlation type, and has two sections: identifying organizational culture based on Hofstede's view and evaluation of the effectiveness of strategy execution. Likert survey is used here, with answers ranging from completely agree, to completely disagree. The respondent should choose one of the 5 scales which he agrees to. The questionnaires were distributed among Payam-e-Noor university managers around the country, using post, fax, and email, during 2012 spring and summer. Cochran formula is used to calculate the sample size as 120 individuals, with 119 acceptable questionnaires collected.

$$
\mathrm{n}=\frac{\frac{\mathrm{z}^{2} \mathrm{pq}}{\mathrm{d}^{2}}}{1+\frac{1}{\mathrm{~N}}\left(\frac{\mathrm{z}^{2} \mathrm{pq}}{\mathrm{d}^{2}}-1\right)}
$$

To increase the validity of research, the questions on the survey were designed to be relevant to the topic. To determine the trust ability (reliability) of the questionnaire, Cronbach alpha was used. 20 questionnaires were primarily distributed among the Payam-e-Noor university managers. Then, using a SPSS software, the following Chronbach Alpha coefficients were derived: 0.723 for the first questionnaire (organizational culture), 0.875 for the second questionnaire (effectiveness of the strategies), and 0.846 for all the questionnaires. The following statistical methods and technics were used for data analysis: Descriptive statistics: including abundance tables, percentage and graphs, Kolmogorov-Smirnov test (variable distributions compared to normal distribution), Pearson correlation coefficient, and statistical significance using a SPSS software tool. To prove the existence, type and strength of relations between organizational culture variables and strategy effectiveness Pearson correlation coefficient is used. A test for the significance of correlation coefficient is also used to determine the independence or relation between variables.

\section{The results}

\subsection{Kolmogorov-Smirnov test (variable distributions compared to normal distribution)}

In interpreting the results, if the significance is more than $0.05 \mathrm{~m}$ then the observed distribution is the theoretical distribution and no difference between these two exists. In other words, variable distribution is closer to normal distribution. Here, the significance of results (0.647) is higher than 0.05 , therefore, we can say that the distribution of responses follows the normal distribution, and observed distribution is similar to theoretical distribution. Thus, parametric tests should be used for evaluating the research thesis. The results are shown in Table 1. 
Table 1

Results of Single Sample Kolmogorov-Smirnov Test

\begin{tabular}{llllllcl}
\hline \multicolumn{7}{c}{ Normal Parameters(a,b) } & \multicolumn{7}{c}{ Maximum differences } \\
\hline Number & Average & Std. dev. & Absolute & Positive & Negative & Kolmogorov-Smirnov Z & Sig. \\
119 & 184.3109 & 19.80736 & 0.063 & 0.068 & -0.044 & 0.738 & 0.647 \\
\hline
\end{tabular}

6.2. First hypothesis: Power distance influences the effectiveness execution of Payam-e-Noor university strategies.

The results in table 2 show that Power distance influences the effectiveness execution of Payam-eNoor university strategies. The correlation coefficient for this variable is 0.182 with the significance level of 0.048 . Therefore, this thesis is proved to at least $95 \%$. In other words, as the high power distance increases, the effectiveness of strategies increases as well, and as the low power distance increases, the effectiveness level decreases.

\section{Table 2}

Pearson Correlation Coefficient between Power Distance and Effectiveness of Strategies

\begin{tabular}{cccccc}
\hline Pearson Correlation Coefficient & Abundance & Average & $\begin{array}{c}\text { Standard } \\
\text { Deviation }\end{array}$ & $\begin{array}{c}\text { Correlation } \\
\text { Coefficient }\end{array}$ & Sig \\
\hline Effectiveness of strategies & 119 & 83.92 & 15.89 & 0.212 & 0.021 \\
$\begin{array}{c}\text { Uncertainty Orientation and } \\
\text { Uncertainty Avoidance }\end{array}$ & 119 & 20.92 & 2.263 & & \\
\hline
\end{tabular}

6.3. The second hypothesis: Uncertainty Avoidance influences the effectiveness execution of Payam-e-Noor university strategies.

The results of Table 3 show that Uncertainty Avoidance influences the effectiveness execution of Payam-e-Noor university strategies. The correlation coefficient for this variable is 0.212 with the significance level of 0.021 . Therefore, this thesis is proved to at least $95 \%$. In other words, as the uncertainty avoidance increases, the effectiveness of strategies increases as well, and as the Uncertainty orientation increases, the effectiveness level decreases.

\section{Table 3}

Pearson Correlation Coefficient between Uncertainty orientation and Uncertainty Avoidance and Effectiveness of Strategies

\begin{tabular}{cccccc}
\hline Pearson Correlation Coefficient & Abundance & Average & $\begin{array}{c}\text { Standard } \\
\text { Deviation }\end{array}$ & $\begin{array}{c}\text { Correlation } \\
\text { Coefficient }\end{array}$ & Sig \\
\hline Effectiveness of strategies & 119 & 83.92 & 15.89 & 0.182 & 0.048 \\
Power distance & 119 & 16.34 & 1.267 & & 0.182 \\
\hline
\end{tabular}

6.4. Third hypothesis: Individualism influences the effectiveness execution of Payam-e-Noor university strategies.

The results of Table 4 show that Individualism influences the effectiveness execution of Payam-eNoor university strategies. The correlation coefficient for this variable is -0.231 with the significance level of 0.011 . Therefore, this thesis is proved to at least 95\%. In other words, as the Individualism increases, the effectiveness of strategies decreases, and as the individualism decrease (collectivism increases), the effectiveness level increase.

\section{Table 4}

Pearson Correlation Coefficient between Collectivism or Individualism and Effectiveness of Strategies

\begin{tabular}{cccccc}
\hline Pearson Correlation Coefficient & Abundance & Average & $\begin{array}{c}\text { Standard } \\
\text { Deviation }\end{array}$ & $\begin{array}{c}\text { Correlation } \\
\text { Coefficient }\end{array}$ & Sig \\
\hline Effectiveness of Strategies & 119 & 83.92 & 15.89 & -0.231 & 0.011 \\
Collectivism or Individualism & 119 & 21.29 & 2.647 & & 0.047 \\
\hline
\end{tabular}


6.5. The fourth hypothesis: Masculinity influences the effectiveness execution of Payam-e-Noor university strategies.

The results in Table 5 show that Masculinity does not influence the effectiveness execution of Payam-e-Noor university strategies.The correlation coefficient for this variable is -0.032 with the significance level of 0.734 . Therefore, this thesis is not proved to at least $95 \%$ and rejected.

Table 5

Pearson Correlation Coefficient between Masculinity and Effectiveness of Strategies

\begin{tabular}{cccccc}
\hline Pearson Correlation Coefficient & Abundance & Average & $\begin{array}{c}\text { Standard } \\
\text { Deviation }\end{array}$ & $\begin{array}{c}\text { Correlation } \\
\text { Coefficient }\end{array}$ & Sig \\
\hline Effectiveness of Strategies & 119 & 83.92 & 15.89 & -0.032 & 0.734 \\
Masculinity or Femininity & 119 & 22.24 & 2.107 & & \multirow{2}{*}{0.07} \\
\hline
\end{tabular}

6.6. Prioritizing the cultural dimensions according to their effect on the effectiveness of strategy execution in Payam-e-Noor University

Considering the results of table 6 and previous explanations, there is a significant relation between Individualism, Uncertainty Avoidance, and High power distance as independent variables, and effectiveness of strategies as the dependent variable. The effect of individualism on the effectiveness of strategies is, regardless of its direction, stronger than that of uncertainty avoidance and high power distance. Based on the results of Tables 5 and Table 6, there is no significant relation, with at least 95\% reliability, between masculinity and strategy effectiveness in Payam-e-Noor University, and this thesis is rejected.

\section{Table 6}

Prioritizing the cultural dimensions according to their effect on the effectiveness of strategy execution in Payam-e-Noor University, based on the correlation coefficient

\begin{tabular}{llccccc}
\hline \multirow{2}{*}{ Pearson Correlation Coefficient } & Abundance & Average & $\begin{array}{c}\text { Standard } \\
\text { Deviation }\end{array}$ & $\begin{array}{c}\text { Correlation } \\
\text { Coefficient }\end{array}$ & Sig \\
\hline 1 & Collectivism or Individualism & 119 & 21.29 & 2.647 & 0.231 & 0.011 \\
2 & $\begin{array}{l}\text { Uncertainty Orientation or } \\
\text { Uncertainty Avoidance }\end{array}$ & 119 & 20.92 & 2.263 & 0.212 & 0.021 \\
\hline 3 & Power Distance & 119 & 16.34 & 1.267 & 0.182 & 0.048 \\
\hline 4 & Masculinity or Femininity & 119 & 22.24 & 2.107 & -0.032 & 0.734 \\
\hline
\end{tabular}

\section{Conclusion}

The results of Table 6 show that Power distance influences the effectiveness execution of Payam-eNoor university strategies. The correlation coefficient for this variable is 0.182 with the significance level of 0.048 . Therefore, this thesis is proved to at least $95 \%$. In other words, as the high power distance increases, the effectiveness of strategies increases as well, and as the low power distance increases, the effectiveness level decreases. According to these results, managers of Payam-e-Noor University believe in high power distance, which conforms to the results of Hofstede studies for Iran. Hofstede results show a relatively higher than average power distance (power orientation) in Iran, but the results for Payam-e-Noor university shows around $91 \%$ (90.8\% to be exact) power distance in this university, which is considered very high. Therefore, powerful individuals are respected in this university and staff thinks that people on top of the hierarchy are right and have the right to decide. Organizations with high power distance are not interested in flat structures. This perfectly conforms to the organizational structure of most of the Iranian organizations, and in particular Payam-e-Noor University. 
The results in Table 6 show that Uncertainty Avoidance influences the effectiveness execution of Payam-e-Noor university strategies. The correlation coefficient for this variable is 0.212 with the significance level of 0.021 . Therefore, this thesis is proved to at least $95 \%$. In other words, as the uncertainty avoidance increases, the effectiveness of strategies increases as well, and as the Uncertainty orientation increases, the effectiveness level decreases. Therefore, this thesis is accepted. The results of Piamennor University fit the results of Hofstede for Iran. According to Hofstede's results from more than 30 years ago, Unceratinty Avoidance is very high in Iran, and managers of Piamennor University also have higher uncertainty avoidance. The level of Unceratinty Avoidance among the managers of Piamennor University is 61.3\%. It seems that Unceratinty Avoidance in Iran has decreased since Hofstede's studies. In societies with high uncertainty avoidance, like Iran and in particular Payam-e-Noor University, there are less innovative ideas. Ambiguity and change is not pleasant in these organizations, every day, and organized methods of doing their tasks. The result of this research confirms the results of Hofstede that puts Iran among countries with high power distance and low Uncertainty Acceptance.

The results of Table 6 show that Individualism influences the effectiveness execution of Payam-eNoor university strategies. The correlation coefficient for this variable is -0.231 with the significance level of 0.011 . Therefore, this thesis is proved to at least 95\%. In other words, as the Individualism increases, the effectiveness of strategies decreases, and as the individualism decrease (collectivism increases), the effectiveness level increases. Therefore, this thesis is accepted.

Based on our results, most of the Piamennor University managers believe in Collectivism (55.5\%, more than half). In collectivist societies, people are expected to prioritize the group goals to their personal goals, interests, and success. In Hofstede's results, Iran is among the countries with higher than average collectivism. Other papers pubished by Hofstede also considers Iran as a relatively Collectivist society. But Mirsepasi (2004) concludes that Individualism is relatively high in Iran, and that Individualism has been gradually decreasing and Collectivism has been gradually increasing in Iran. As Piamennor University required collectivism to achieve its goals, and collectivism is encouraged in this University, university culture has also moved toward Collectivism.

The results in Table 6 show that Masculinity does not influence the effectiveness execution of Payam-e-Noor university strategies. The correlation coefficient for this variable is -0.032 with the significance level of 0.734 . Therefore, this thesis is not proved to at least $95 \%$ and rejected. Based on the results of this research, management of Piamennor University is femininity-oriented. $64 \%$ of the managers believe in female-centered society. Based on this view, both men and women take variety of jobs in this university, regardless of their sex. In Hofstede's results, femininity and masculinity in Iran were almost equal 30 years ago. Mirsepasi, as well, refuses strong violence in social relations, and defines Iran as an emotional and sensational society. As the population of educated women is now equal to men, and women are also capable of serving in different jobs, passive goal-oriented behavior has also increased in Iran, and the society has become female-centered. But the results do not prove a significant relation between masculinity/femininity dimensions with effectiveness of strategies.

\section{References}

Aa'rabi, S, M., Hedayati, S, H. (2010). Presenting a Model for Designing Culture-Based Strategy. Human Resource management researchers, 3, 127-145.

David, F. R. (2001). Strategic Management. New Jersey: Prentice-Hall, Inc. 8th ed.

Davis, S. M. (1984). Managing corporate culture. Cambridge, MA: Ballinger Publishing Company. Esmaeelpour. H. (2011). International Business, Tehran, Neghahe danesh.

Hatch, M.J. (2006). Organization Theory: Modern, symbolic, and postmodern perspectives. 2nd Ed. Oxford University. 
Hoskisson, R. E., Hitt, M. A., \& Ireland, R. D. (2008). Competing for advantage. South-Western Pub. Joseph, P., Igor, P. (1999). Entrepreneurship development in public enterprises, International labour organization.

Kaplan, R. S., \& Norton, D. P. (2001). The strategy-focused organization: How balanced scorecard companies thrive in the new business environment. Harvard Business Press.

Mirsepassi, N. (2004). Human resources strategic management and labour relations. 23nd ed. Tehran: Mir, p 55.

Noble, C. H. (1999b). The eclectic roots of strategy implementation research.Journal of Business Research, 45(2), 119-134.

Noble, C. H., \& Mokwa, M. P. (1999). Implementing marketing strategies: developing and testing a managerial theory. The Journal of Marketing, 57-73.

Ofori, D., \& Atiogbe, E. (2012). Strategic Planning in Public Universities: A Developing Country Perspective. Journal of Management and Strategy, 3(1), 67.

Okumus, F. (2001). Towards a strategy implementation framework.International Journal of Contemporary Hospitality Management, 13(7), 327-338.

Pearce, J. A., \& Robinson, R. B. (1991). Formulation, implementation, and control of competitive strategy. Irwin.

Peters, T. J., \& Waterman, R. H. (2004). In search of excellence: Lessons from America's best-run companies. HarperBusiness.

Pettigrew, A. M. (1985). The awakening giant, change and continuity in ICI.Oxford: Blackwell).(1987),'Context and Action in the Transformation of the Firm', Journal of Management Studies, 24(6), 649-70.

Robbins, S. P. (1990). Organization Theory: Structures, Designs, And Applications, 3/e. Pearson Education India.

Robbins, S. P. (2005). Essentials of organizational behavior. Prentice Hall.

Sashittal, H. C., \& Wilemon, D. (1996). Marketing implementation in small and midsized industrial firms: an exploratory study. Industrial Marketing Management, 25(1), 67-78.

Skivington, J. E., \& Daft, R. L. (1991). A Study of organizational 'Framework'and 'Process' modalities for the implementation of business-level strategies decisions. Journal of Management Studies, 28(1), 45-68.

Thompson, A. A., Strickland, A. J., \& Gamble, J. E. (1998). Strategic management: Concepts and cases. Irwin/McGraw-Hill.

Yang, L., Sun, G. H., \& Eppler, M. (2009). Making strategy work: A literature review on the factors influencing strategy implementation. Handbook of research on Strategy Process, 165-181. 